\title{
Support for Paid Family and Medical Leave in New Hampshire
}

\section{Kristin Smith}

$\mathrm{I}$ n October 2018, the last period for which we conducted public opinion research, support for a paid family and medical leave program was high. Seventy-eight percent of New Hampshire residents stated support for a program that would provide a portion of wages to workers taking leave for personal or family medical reasons. ${ }^{1}$ This was statistically unchanged from earlier research conducted in 2016. Women registered higher levels of support for paid family and medical leave insurance than men, and those with a liberal or moderate political ideology reported higher support than those with a conservative ideology (Figure 1). Levels of support did not vary significantly between regions in the state.

\section{FIGURE 1. SUPPORT FOR A PAID FAMILY AND MEDICAL LEAVE INSURANCE PROGRAM, NEW HAMPSHIRE RESIDENTS}

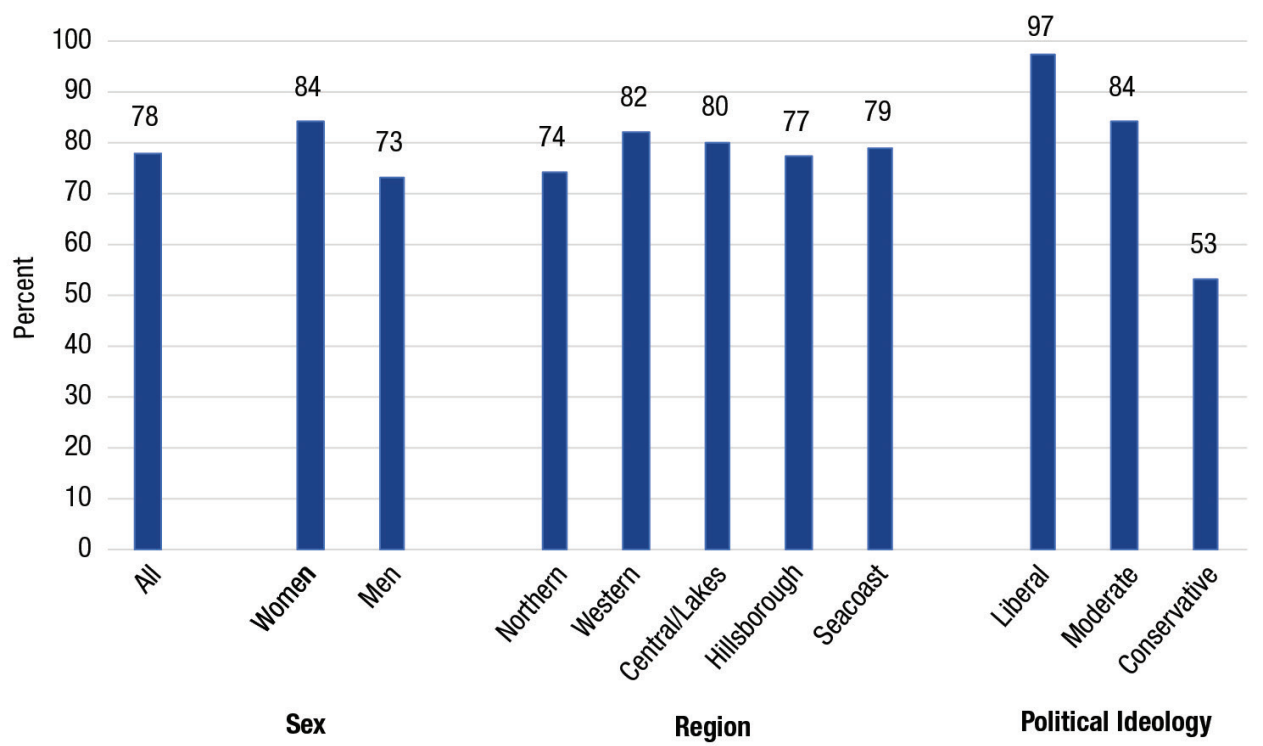

Note: Based on question asking if support or oppose New Hampshire adopting a paid family and medical leave program that would provide a portion of wages through a statewide fund to all workers to take leave from work for a limited time period for serious personal or family medical reasons. Support includes those who strongly or somewhat support. Statistically significant gender difference at $p<.01$; statistically significant difference between all political ideologies at $p<.001$; no statistically significant differences by region. Source: Paid Family and Medical Leave Topical Module, Granite State Poll, October 2018.

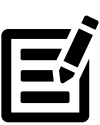

Concord Monitor coverage on April 14, 2019, of a recent Carsey brief on job protection and wage replacement, in the context of a public paid family and medical leave insurance program, noted that the brief did not include information on public opinion regarding a paid family and medical leave program for New Hampshire generally, and specifically on the question of whether a program should be mandatory or voluntary. This data snapshot addresses that question.

See related publications at carsey.unh.edu

- Job Protection and Wage Replacement: Key Factors in Take Up of Paid Family and Medical Leave Among Lower-Wage Workers (April 2019)

- Paid Family and Medical Leave in New Hampshire: Who Has It? Who Takes It? (September 2016)

- Over 80 Percent of New Hampshire Residents Support Paid Family and Medical Leave Insurance (August 2016) 
Related to the specific question of whether a program should require participation or be voluntary: more than two-thirds, 69 percent, of New Hampshire workers supported the inclusion of a requirement that all workers participate and pay into a paid family and medical leave insurance program. Patterns in support for this allworker approach follow those seen in overall support for a program, namely men and those with a conservative ideology registered lower support than their counterparts, and differences by region were not statistically significant (Figure 2).

\section{FIGURE 2. SUPPORT FOR A REQUIREMENT THAT ALL WORKERS PARTICIPATE AND PAY INTO A PAID FAMILY AND MEDICAL LEAVE INSURANCE PROGRAM, NEW HAMPSHIRE WORKERS}

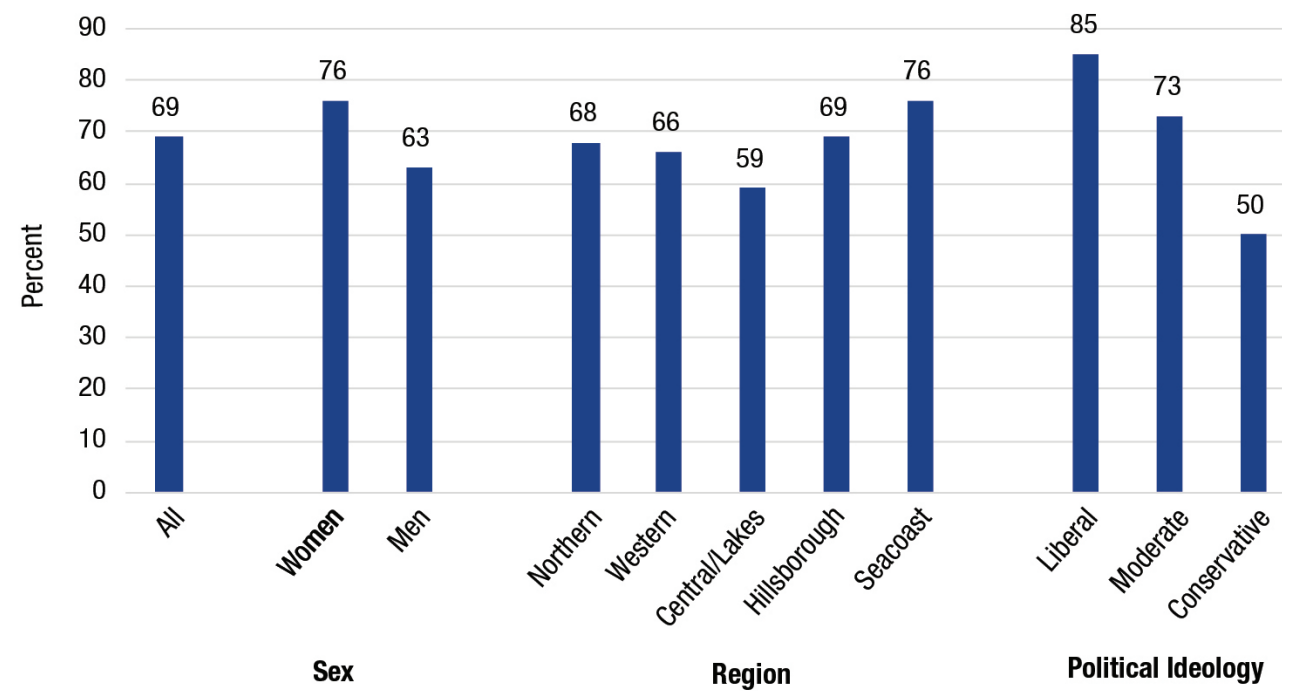

Note: Based on question asking if support or oppose a requirement that all workers participate and pay into a paid family and medical leave insurance program. Support includes those who strongly or somewhat support. Statistically significant gender difference at $\mathrm{p}<.01$; statistically significant difference between all political ideologies at $\mathrm{p}<.05$; no statistically significant differences by region. Source: Paid Family and Medical Leave Topical Module, Granite State Poll, October 2018.

When those who opposed an all-worker program were asked if their opinion would change if they were told that allowing workers to opt out of the program would result in those who opted in paying substantially more for coverage, 34 percent changed their mind and no longer opposed the requirement of participation. This raised support for an all-worker program to 78 percent of workers. Simulation models estimate premium costs 30 to 60 percent higher under a voluntary opt-in program than under an all-worker program, depending on the participation level. ${ }^{2}$

\section{Endnotes}

1. These include caring for a newborn or newly adopted child or a seriously ill family member, or tending to one's own serious illness.

2. Jeff Hayes and Meika Berlan, "Costs and Benefits of Family and Medical Leave for New Hampshire Workers" (IWPR, Washington, DC: 2016).

Kristin Smith is a family demographer at the Carsey School of Public Policy and research associate professor of sociology at the University of New Hampshire (kristin.smith@ unh.edu). 